\author{
EVS27 Symposium \\ Barcelona, Spain, November 17-20, 2013
}

\title{
The business case of electric vehicle quick charging - no more chicken or egg problem
}

\author{
Joni Markkula ${ }^{1}$, Antti Rautiainen ${ }^{1}$ Pertti Järventausta ${ }^{1}$ \\ ${ }^{1}$ Department of Electrical Engineering, Tampere University of Technology, Korkeakoulunkatu 3 FI-33101 Tampere, \\ joni.markkula@tut.fi
}

\begin{abstract}
Short Abstract
One of the major problems slowing down electrical vehicle (EV) adoption is the lack of sufficient infrastructure. We can often hear of the chicken or egg problem. But the charging infrastructure problem is smaller than generally thought. By analysing the economics of EV quick charging stations it can be shown that building and sustaining adequate EV charging network does not require massive investments, and on the other hand, profitability of a single charging station can be achieved with a moderate number of EVs due to high polarisation of customer needs, leading to daily charging needs of certain user groups.
\end{abstract}

\section{Introduction}

The three major factors affecting the wide spread adoption of electrical vehicles (EV) are most often mentioned to be 1 . high prices 2 . short operational range 3. lack of charging infrastructure [1]. The first two can be seen as problems of mass production and battery technology development. The purpose of this article is to present a solid argumentation how to overcome the problem of inadequate charging infrastructure e.g. the third of these common obstacles for EV adoption.

When EV charging infrastructure is planned, it is often compared to gasoline station network. But the internal combustion engine car (ICE) and EV have several important differences. The key differences are the duration of gas station visit, price of energy and the cost of building the infrastructure. Some of these differences are in advance of ICE, some of EV. The major problem unsolved is a working business model, which provides profit for charging station owners and is at the same time attractive to customers thus making the business viable in the long term. This article presents a suggestion of a business model and the economical reasoning behind the quick charging station profitability.

\section{EV charging service models and customer value}

EV charging has major differences when compared to ICE fuelling which are not only technological differences (gasoline vs. electricity) but also user experience differences. Regular car users have been used to fuel their cars in a very stable manner: drive to gas station once a week or month, fuel your car for few minutes and pay the bill with cash or credit card. This method provides fuel for driving hundreds of kilometres. Gas station visit is a similar experience in almost all parts of the world.

EV charging has only little resemblance. The plugs come in many standards, power levels can differ significantly and the access to charging stations is still a mystery. Operational range of electric vehicle after charging depends on charging power and duration. Also the battery sets limitations. Even more interesting is the need for charging- some customers might never enter a public charging station due to sufficient home charging equipment whereas for some customers daily visits to quick charging station is the only option to operate vehicles effectively (e.g. delivery companies or in intercity traffic). The key differences of EV charging and ICE filling from customer perspective are presented in table 1. 
Table 1. EV charging and ICE filling differences from consumer point of view

\begin{tabular}{|l|c|c|}
\hline & EV & ICE \\
\hline Duration of visit & $20 \mathrm{~min}$ to $10 \mathrm{~h}$ & $2-5 \mathrm{~min}$ \\
\hline Operational range & $100-300 \mathrm{~km}$ & $500-1100 \mathrm{~km}$ \\
\hline $\begin{array}{l}\text { Price of Energy } \\
\text { per } 100 \mathrm{~km}\end{array}$ & $2-5 €$ & $8-14 €$ \\
\hline Public access & difficult & easy \\
\hline Home access & easy & not possible \\
\hline
\end{tabular}

Even when electricity cannot be described as a sparse commodity in developed countries, EV drivers still face the difficulty of purchasing electricity in public locations. EV driver travelling through Europe would encounter several situations where he would be left without any kind of option of purchasing electricity for example from current gas stations, hotels or restaurants. Electric grid connections exist practically everywhere but yet they cannot sufficiently fulfil the needs of EV drivers.

The problem lies within different service models and their values to customers. Zwicky [2] presented a method of comparing different solution options when facing a multifaceted problem. This method is called the morphological approach. The basic idea is simple: different factors of the problems are categorized and to each category the possible attributes are described. In EV charging context an example is presented in figure 1, where categories are technology, power, identification, payment, service provider and additional services. Each category consists of four to six attributes. The attributes are organized from left to right, the left end presenting least complexity and smallest service level. Moving to the right in class increases complexity and provides higher customer service level and thus higher customer value.

The morphological field provides quickly an excellent view of the available solution possibilities and helps illustrating the value of different services provided. In contrast to table 1, morphological box illustrates the service provider perspective and the picture with the table together create common understanding of problems and possible solutions.

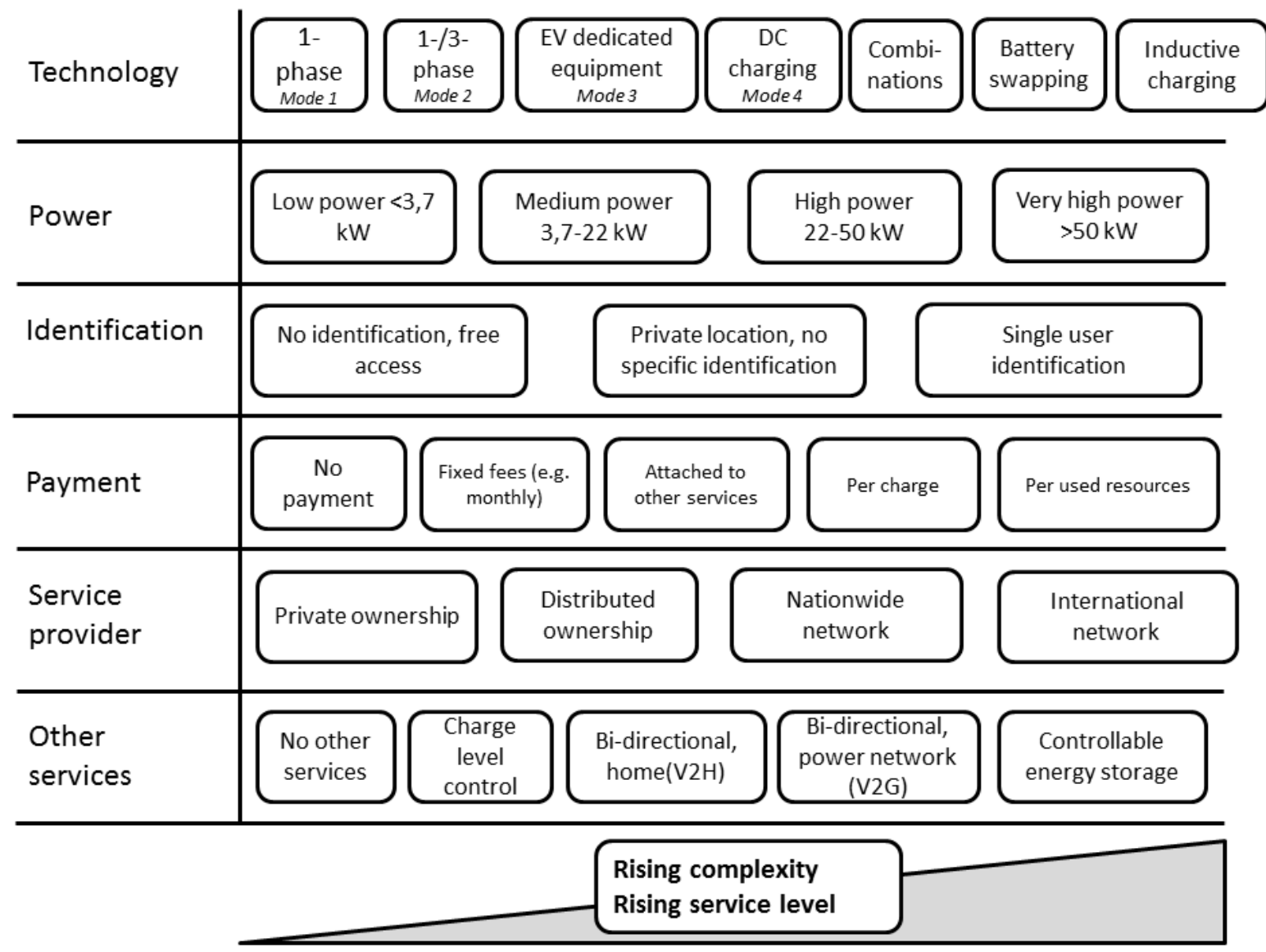

Figure 1. Different service models for EV charging 
As we can see the first set of attributes (left side) is quite easy to fulfil: 1-phase, $3.7 \mathrm{~kW}$ charging without identification and payment in a privately owned location. This we can realize almost in every modern building. The problem is low level of service. The charging happens in random places and takes several hours to charge $100 \mathrm{~km}$ of range. This is not enough to encourage EV adoption. On the other hand, the right side of figure seems to be a future vision: wireless charging with high power, payment based on usage, access to charging internationally and automatically plus price discounts by offering ancillary services [3] for power system actors. The problem is that building this kind of infrastructure is expensive and demands several actors to involve and co-operate. The near future is somewhere between the two extremes.

What figure 1 implies, is that $\mathrm{EV}$ drivers should be provided higher value services rather than trying to avoid the costs thus not satisfying user expectations. Charging station service cannot compete with home charging solutions in price but they can offer something that home charging cannot.

\section{Cost structure of EV quick charging}

Financial analysis in this chapter is constructed for single DC quick charging station with $50 \mathrm{~kW}$ maximum power, which is assumed to be the basis of a public charging network. Based on the service model description presented before, it provides a realistic near-future proposition for creating sufficient service level with existing technology.

The main costs of EV charging stations can be split to three categories: investment costs, fixed costs and variable costs. Disposal costs are negligible compared to other lifetime costs and are therefore left out from the analysis. The price estimates presented in the text and in table 2 are based on industry expert interviews, electric company price lists from Finland and Nordpool spot electricity market prices. The assumptions used are 8 years operational lifetime, $8 \%$ credit interest and no VAT included in prices.

Investment costs consist of quick charging station equipment (33 $000 €)$, electricity grid connection $(4000 €)$ and construction costs in the location (5000 €). The investment costs are estimated with rather pessimistic prices, especially the station equipment price, leaving some space for positive surprises. Fixed costs derive from electricity network connection monthly fees $(300 € /$ month) and service and maintenance costs (2000 $€ /$ year). The variable costs consist of energy costs $(50 € / \mathrm{MWh})$ and electricity transfer costs $(30 € / \mathrm{MWh})$. Billing costs are not included.

Table 2. EV quick charging station costs

\begin{tabular}{|l|c|}
\hline Investment costs & $42000 €$ \\
\hline Fixed costs (per year) & $5600 €$ \\
\hline Variable costs (per MWh) & $80 €$ \\
\hline
\end{tabular}

If the investment costs are spread over the lifetime of charging station, the yearly cost is less than $4800 €$. This means that more important than the absolute values of investment costs, is to understand their proportional size compared to yearly fixed costs. The investment has a high effect on cash flows if funded with equity, but smaller effect on yearly profit. We can estimate that the charging station yearly fixed costs are in the range of 10-12 $\mathrm{k} €$ including the charging station investment cost payments and variable costs 80 $€ / \mathrm{MWh}$

When compared internationally, the situation and numbers don't change significantly. The cost to charging station equipment is equal and small differences occur due to varying labour costs, electric grid connection prices or utility companies' base fees as well as in energy prices. Based on the statistics we can conclude the energy and electricity transfer prices to be in same proportion $(80-120 € / \mathrm{MWh})$ for industrial customers and grid connection costs not exceeding the values used on these calculations at least in Germany $[4,5]$.

\subsection{Cost of charging network}

Based on the cost summary of table 2 we can estimate the cost of a more comprehensive charging network. The need for quick charging stations is still a mystery, but we can try to approach it from the service offering perspective or user need perspective. The service offering of one quick charging station is estimated to be 12-17 full charges per day, which follows from the full charge duration but also from customer preferences i.e. charging needs during morning, lunch time or after-work hours and not in in the night. This means the station capacity utilisation ratio of less than $30 \%$. This would contribute energy up to $340 \mathrm{kWh}$ per day, which translates to $1700 \mathrm{~km}$ of electrical kilometres $(0.2 \mathrm{kWh} / \mathrm{km})$. If we consider the average driving distance of a vehicle to be about $40 \mathrm{~km}$ per day one station would serve more than 40 users daily [6]. It is also expected, that domestic charging is used whenever possible leading to substantially lower number of stations needed. If we estimate that one third of charging takes place in public locations, a fleet of 50000 
electric vehicles would require a charging network of about 400 stations. The investment size for such a network would be $16 \mathrm{M} €$ and the yearly fees $2,2 \mathrm{M} €$. That is considerably less than the development costs of a single car model. One must remember an important thing: the size of this investment is a pessimistic estimate and the cost of charging equipment can be expected to be considerably lower. In addition if we evaluate that domestic charging would present at least two thirds of the charging, the need for quick charging network lowers significantly. At the moment only Estonia has a functioning example of comprehensive charging network of 160 charging station with five years of full service contract on a tender price of 6,6 M€ [7].

\section{Pricing the quick charging}

What is the right price for EV quick charging? As shown in figure 1, different service levels offer different customer value, and prices should change accordingly. Marketing literature provides good propositions when planning the pricing structure. Kottler describes different pricing methods of which three are presented [8]:

- Mark-up pricing: exceeding the operative costs

- Going-rate pricing: the current market price, price offered by existing competitors

- Value pricing: how much value does the service provide for customer

Choosing the right price for $\mathrm{EV}$ quick charging is an optimisation problem of many factors: revenues must exceed the costs, market price doesn't exist yet and value can be determined in multiple ways (e.g. compared to gasoline cost or pricing unique service). Pricing involves also aspects of marketing strategy and the customer perception of price fairness [9]. In the long run the price per charge must exceed the costs, unless additional revenue streams are available e.g. paid commercials, other fixed income. The upper price limit for quick charging can be derived from the price of competitive solutions. ICE cost per $100 \mathrm{~km}$ is with modern cars about 9-13 $€$ in Eurozone. At the same time one should remember that EV charging doesn't necessarily take place only in public charging stations so the price limit is not directly the same as with gasoline because of lower user costs during a longer period. The value of quick charging is complicated question: if the only way to travel between two cities within reasonable time is quick charging we can assume that the customer is willing to pay a larger premium as he would be in the case when charging time is irrelevant.

For the example calculations the following figures are used. The customer price for quick charging is $8 €$ including VAT. The customer is offered with $50 \mathrm{~kW}$ (DC) charging power which will fill $20 \mathrm{kWh}$ energy need of the battery in 25 minutes if peak charging power is maintained. The $8 €$ price for quick charging is mostly a matter of opinion and holds many assumptions. At the moment low power EV charging is offered for free in many countries or areas [10], EV charging is offered as a complementary service in e.g. parking houses or quick charging is free for limited time in pilot locations. That is what makes it hard to estimate true customer value and willingness to pay. There are also contract models providing access to wide charging network where customer expectations of one time charging fee is difficult to measure [11]. From the owner side it should be noted that the marginal cost of offering service to customer is low (2-3€ per $20 \mathrm{kWh})$ and the domestic charging cost is low, creating put downwards pressure on the price setting.

\section{Forecasting the profitability and cash flows}

Due to low variable costs the active use of station services is the key to profitability. We notice that the most important factor of charging station success is committed customer who visits the station constantly. This can be achieved by providing the customers a service that serves their needs (right plug, acceptable duration of charging) where they prefer (shopping centre, parking house) rather than trying to minimise the investment costs or imitate the gas station infrastructure.

Table 2 illustrates that to run a single quick charging station profitably doesn't necessarily require high EV rates, but rather a handful of dedicated customers. The break-even number is roughly 2500 full charges (20 $\mathrm{kWh}$ ) per year, which means less than seven customer visits per day. Seven daily visits means either 21 customers visiting every three days or less than four customers visiting twice a day.

Table 2. Quick charging profits with different quick charge quantities per year

\begin{tabular}{|l|l|l|l|l|l|}
\hline Number of quick charges & 900 & 1500 & 2500 & 3500 & 5500 \\
\hline Total yearly costs & 14176 & 14656 & 15616 & 17216 & 22016 \\
\hline Revenue & 3870 & 5805 & 9675 & 16125 & 35475 \\
\hline Profit & -7451 & -4541 & 309 & 5159 & 14859 \\
\hline
\end{tabular}


Table 3 presents the yearly profits of charging station with predict customer visits per year. The maximum amount is limited by the station service capacity. In the beginning the number of user visits is modest but is expected to grow with the number of EVs.

Table 3. Charging station profitability prediction

\begin{tabular}{|l|c|c|c|c|c|c|c|c|}
\hline Year & $\mathbf{1}$ & $\mathbf{2}$ & $\mathbf{3}$ & $\mathbf{4}$ & $\mathbf{5}$ & $\mathbf{6}$ & $\mathbf{7}$ & $\mathbf{8}$ \\
\hline User visits & 900 & 1800 & 3000 & 4500 & 6000 & 6000 & 6000 & 6000 \\
\hline Revenue & 5805 & 11610 & 19350 & 29025 & 38700 & 43548 & 43548 & 43548 \\
\hline Costs & 11774 & 13214 & 15134 & 17534 & 19934 & 19934 & 19934 & 19934 \\
\hline Operating profit & -5969 & -1604 & 4216 & 11491 & 18766 & 23614 & 23614 & 23614 \\
\hline
\end{tabular}

By estimating the yearly customer visits in the station we can predict the cash flows of station owner and also other value network stakeholder like energy retailer, distribution network operator (DNO), and service and maintenance provider. The customer price of $8 €$ generates approximately $6,5 €$ revenue for station owner after taxes. User visit equals the full charging service described in table 3. Neither the financer's nor station supplier cash flows are presented.

In table 4 can be found the cash flow predictions based on the calculations and assumptions made before. It is also assumed that the station is financed with debt only. If the case would change to equity financing, then the first year cash flow would be substantially more on negative side (investment costs paid on first year) and the future years approximately $4800 €$ more positive leading cumulatively to same cumulative value plus interest.

Table 4. Cash flows of different participants

\begin{tabular}{|l|c|c|c|c|c|c|c|c|c|}
\hline Year & $\mathbf{1}$ & $\mathbf{2}$ & $\mathbf{3}$ & $\mathbf{4}$ & $\mathbf{5}$ & $\mathbf{6}$ & $\mathbf{7}$ & $\mathbf{8}$ & SUM \\
\hline Station owner & -5969 & -1604 & 4216 & 11491 & 18766 & 23614 & 23614 & 23614 & 97339 \\
\hline Energy retailer & 900 & 1800 & 3000 & 4500 & 6000 & 6000 & 6000 & 6000 & 34200 \\
\hline DNO & 8140 & 4680 & 5400 & 6300 & 7200 & 7200 & 7200 & 7200 & 53320 \\
\hline S\&M provider & 7000 & 2000 & 2000 & 2000 & 2000 & 2000 & 2000 & 2000 & 21000 \\
\hline
\end{tabular}

The station owner has the potential for the highest profits, but he is also bearing all the financial risk with the financing institution. The other participants are paid for their services and these cash flows don't represent their profits but mere revenues. We see from table 4 that there are several parties involved who should have clear interest on EV charging business as it provides the possibility expanding their services and creating new business.

It is worth emphasizing that these calculations apply only to one charging station and cannot be directly extrapolated to estimate the profitability of a charging network or the situation in a more competitive environment. In case of wider charging network coverage it might happen that the customer visits decrease per station and profits are cannibalised by competition. Some Japanese studies implicate also that even when quick charging stations are expected and wanted, the use of the stations may be less than assumed [12].

\section{Creating the business model}

Based on the findings of section 5, an idea of a business model can be constructed. The first step is to understand what customers need (or might need). Magretta describes a business model as a way of answering few essential questions [13]:

- Who is the customer?

- What does the customer value?

- Can that value be offered in a profitable way?

Based on the discussion before, the answer to these question would be following: the customer is an EV user who needs quick charging services in order to operate his vehicle efficiently either in the city area or on longer distance trips. He drives 100-300 kilometres per day and has no time for long pauses but is unwilling to invest to a private quick charging station. Customer values good location of the station, and the additional services that are offered during the charging (lunch, coffee, internet connection) and therefore commits to constant visits on chose locations. And yes, the charging station profitability can be achieved even when the price for EV quick charging is less than gasoline costs per kilometre as described in chapter 4.

When talking about business models it is hard to neglect the business model framework by Alexander Osterwalder. Osterwalder suggests business model to consist of nine building blocks, which are value proposition, customer segment, customer relationship, channels, key resources, key partners, key activities, costs and revenue streams $[14,15]$. Compared to Magretta the key questions he adds are how to get, keep and 
grow customer relationships, and how to run the operations of the company (resources, partners, activities, channels). The model is extremely useful for companies considering jumping into charging business, but in this case it includes a large amount of variables that cannot be answered on generic level but analysed per company.

At the moment the world of EV charging is not lacking business model propositions. Some presenting the variety are for example Better Place, which offered a totally different business model of owning the batteries and selling the use of batteries to clients by battery swapping. Better Place ended up to bankruptcy, but now Tesla motors is confident enough to begin providing similar service to customers [16]. The difference between the companies is that Tesla also builds the cars and thus operates in their own ecosystem, whereas Better Place was dependent on car manufacturers' co-operation. Tesla motors is also providing high power DC charging for free to customers who own the Tesla Model S car [17]. The cost of charging network is included in the price of the car. Some companies, like the Danish Clean Charge, offer charging equipment installations with maintenance, and charging power control for vehicle fleets that could later enable for example load-balancing services for power grid [18]. The question is, which of these business model propositions creates the highest returns in the future.

\subsection{Validating the business model}

Existing business models are fairly easy to describe but validating new ones is more challenging. New business models consist of a number of hypothesis and assumptions how things are or will be. The most important variable is the customer - without a paying customer there is no viable business. After identifying customer value the other parts of business model need to support the value proposition delivery. We can say that there are two stages in the new business development - searching for new business models and executing validated business models. The same implies to new and existing companies if the business area is new.

In the phase of searching the business model it is important not to trust the existing assumptions of customer expectations but to test them. The most efficient method of testing customer value is to see if he pays for the product or service. In the context of EV charging the customer should be engaged to the planning the location of stations and asked the question of the correct price, which are critical factors for success. Often the customer value is much more than mere "money-energy-time"-question. The losses due to failure in the beginning are measured in working hours or in this particular EV charging case, tens to hundreds of thousands of euros. The scale of costs is very small compared to the cost of building and sustaining a charging network with some millions of euros in investment and yearly costs.

After learning the customer preferences in one location the charging network can be expanded with more confidence. This is described as the execution phase. The importance of failing less cannot be overemphasized. Large failures can be critical for any company and can also lead to loss of credibility of the business sector.

\subsection{Risks in EV charging business}

The obvious risk in EV charging business is the lack of customer i.e. EV drivers needing public charging. Nevertheless, we have seen that the user base doesn't need to be vast in order for single charging station owners to generate profit. The question of working capital is essential due to investment costs and also financial losses in the early days of station history. Both of these issues can be mitigated through longer-term deals with customers securing cash flow and customer visits for a station.

Choosing the technology plays an important role. The station owner is dependent on car manufacturers' and standardisation organisations' decisions. If the future development would make the chosen technology to be invalid, the cost of switching would be large, almost half of the investment costs with present prices. The station prices are expected to decrease in the future making the long-term risk of technology smaller.

After the viable business case is proven, it can be assumed that the competition will increase. This is not in favour of the pioneering companies, but the customers' willingness to change service provider is much smaller if they have received good service in the past and are familiar with visits to preferred locations.

\section{Conclusion and future studies}

The study presents two important findings. First, in order to turn one EV quick charging station profitable the target customers need to be found. Target customers are users who need quick charging frequently to enable efficient utilisation of vehicle or vehicle fleets e.g. delivery companies, professional transport and public service vehicles, and are able to commit to frequent use of charging service. The absolute number of electric vehicles in chosen area is less significant. Second, the necessary investment needed to build a 
sufficient charging infrastructure for EVs is not unreachable. The need for quick charging stations is lower than commonly expected as customers can charge in domestic locations or parking houses. Quick charging acts mostly as an enabler.

Based on these findings building the quick charging infrastructure should be seen as the first and the easiest step to wider electric mobility. The business model must not imitate the gasoline station infrastructure but the new infrastructure can be constructed more freely based on new customer preferences. EV charging can be seen as viable business already now. It should be also noted that the estimated future size of the market for public charging is probably overestimated. This means that the ones creating committed customer relationships in the beginning will gain large market shares.

The future studies in the field should concentrate on analysing the customer behaviour in real life situations. So far we have seen a range of studies examining the willingness to pay for different EV related properties, but they don't necessarily reflect the true behaviour. Also the locations of public charging stations should be examined to achieve a clear image of customer preferences.

\section{References}

[1] Hidrue, M. 2011 Willingness to pay for electric vehicles and their attributes. Resource and Energy Economics 33 (2011) 686-705.

[2] Zwicky, F.Wilson A.G. 1967. New Methods of Thought and Procedure. Contributions to the Symposium on Methodologies, May 22-24, 1967, Pasadena.

[3] Rautiainen, A. Markkula, J. Repo, S. Kulmala, A. Vuorilehto, K. Järventauta, P. 2013. Plug-in vehicle ancillary services for a distribution network. EVER2013 conference. Monte Carlo.

[4] Eurostat. Energy price statistics - Statistics Explained (2013/7/2). Retrieved 26.6.2013 from http://epp.eurostat.ec.europa.eu/statistics_explained/index.php/Energy_price_statistics\#

[5] SWM. 2013. Preisblatt Netzanschlüsse. Retrieved 27.6.2013.

[6] Finnish ministry of Transport. 2012. Person traffic study. ISBN 978-952-255-102-3. http://www.swm-infrastruktur.de/dms/swm-infrastruktur/dokumente/preise-netzanschluesse.pdf

[7] Estonian ministry of foreign affaris. 2012. Press release. Retrieved 15.4.2013 from http://www.vm.ee/?q=en/node/13723

[8] Kotler, P. 1998. Marketing Management. $7^{\text {th }}$ edition. pp.482-488. Prentice Hall

[9] Lan, X. Monroe, B. Cox, J.. 2004. The Price Is Unfair! A Conceptual Framework of Price Fairness Perceptions. Journal of Marketing: October 2004, Vol. 68, No. 4, pp. 1-15.

[10] Oslo kommune bymiljoetaten. 2011. EV charging points in Oslo - 400 public charging points in 4 years 20082011. p. 8.

[11] Elmo. 2013. [WWW] Price list. Retrieved 4.6.2013 from http://elmo.ee/pricing/

[12] Anegawa, T. Tokyo Electric Power Company. 2010. Development of Quick Charging System for Electric Vehicle. World energy congress. Montreal.

[13] Magretta, J. 2002. Why business models matter. Hardvard Business Review. May 2002.

[14] Osterwalder, A. 2004. The business model ontology - a proposition in a design science approach. Doctoral dissertation. University of Lausanne.

[15] Osterwalder, A. Pigneur, Y. 2010. Business model generation: A Handbook for Visionaries, Game Changers, and Challengers. Wiley.

[16] Financial Times. 2013. [WWW] Electric car group Better Place files for bankruptcy. Published 26.5.2013.

[17] Tesla Motors. 2013. [WWW]. Retrieved 10.7.2013 from http://www.teslamotors.com/supercharger

[18] Clean Charge. 2013. [WWW] Company website http://www.cleancharge.dk/about-cc/

Joni Markkula received his M.Sc degree from Tampere University of Technology in 2013. He is now working as a researcher at Tampere University of Technology. His main interest focuses on business logic and business models in power system context.

Antti Rautiainen received his M.Sc degree from Tampere University of Technology in 2008. He is now working as a researcher towards doctoral degree at Tampere University of Technology. His main interest focuses on the effects of plug-in vehicles to electric power systems, ancillary service possibilities of plug-in vehicles and new load control schemes.

Pertti Järventausta received the Dr.Tech. degree in Electrical Engineering from Lappeenranta University of Technology in 1995. At present he is a professor at the Department of Electrical Energy Engineering of Tampere University of Technology. The main interest focuses on the electricity distribution and electricity market. 